\title{
Pragmatic Recommendations for the Prevention and Treatment of Acute Kidney Injury in Patients with COVID-19 in Low- and Middle-Income Countries
}

\author{
Kristina E. Rudd, ${ }^{1 \star}$ Elif A. Cizmeci, ${ }^{2}$ Gabriela M. Galli, ${ }^{3}$ Ganbold Lundeg, ${ }^{4}$ Marcus J. Schultz, ${ }^{5,6,7}$ and Alfred Papali ${ }^{8}$ for the \\ COVID-LMIC Task Force and the Mahidol-Oxford Research Unit (MORU) \\ ${ }^{1}$ Department of Critical Care Medicine, University of Pittsburgh, Pittsburgh, Pennsylvania; ${ }^{2}$ Interdepartmental Division of Critical Care Medicine, \\ University of Toronto, Toronto, Canada; ${ }^{3}$ School of Medicine, University of Pittsburgh, Pittsburgh, Pennsylvania; ${ }^{4}$ Department of Critical Care and \\ Anaesthesia, Mongolian National University of Medical Sciences, Ulaanbaatar, Mongolia; ${ }^{5}$ Department of Intensive Care, Amsterdam University \\ Medical Centers, Amsterdam, The Netherlands; ${ }^{6}$ Mahidol-Oxford Tropical Medicine Research Unit (MORU), Mahidol University, Bangkok, \\ Thailand; ${ }^{7}$ Nuffield Department of Medicine, Oxford University, Oxford, United Kingdom; ${ }^{8}$ Division of Pulmonary \& Critical Care Medicine, Atrium \\ Health, Charlotte, North Carolina
}

\begin{abstract}
Current recommendations for the management of patients with COVID-19 and acute kidney injury (AKI) are largely based on evidence from resource-rich settings, mostly located in high-income countries. It is often unpractical to apply these recommendations to resource-restricted settings. We report on a set of pragmatic recommendations for the prevention, diagnosis, and management of patients with COVID-19 and AKI in low- and middle-income countries (LMICs). For the prevention of AKI among patients with COVID-19 in LMICs, we recommend using isotonic crystalloid solutions for expansion of intravascular volume, avoiding nephrotoxic medications, and using a conservative fluid management strategy in patients with respiratory failure. For the diagnosis of AKI, we suggest that any patient with COVID-19 presenting with an elevated serum creatinine level without available historical values be considered as having AKI. If serum creatinine testing is not available, we suggest that patients with proteinuria should be considered to have possible AKI. We suggest expansion of the use of point-of-care serum creatinine and salivary urea nitrogen testing in community health settings, as funding and availability allow. For the management of patients with AKI and COVID-19 in LMICS, we recommend judicious use of intravenous fluid resuscitation. For patients requiring dialysis who do not have acute respiratory distress syndrome (ARDS), we suggest using peritoneal dialysis (PD) as first choice, where available and feasible. For patients requiring dialysis who do have ARDS, we suggest using hemodialysis, where available and feasible, to optimize fluid removal. We suggest using locally produced PD solutions when commercially produced solutions are unavailable or unaffordable.
\end{abstract}

\section{INTRODUCTION}

Acute kidney injury (AKI) is a major cause of morbidity and mortality worldwide. ${ }^{1}$ Hypotension and dehydration, which are common complications of acute infection, are among the leading causes of $\mathrm{AKI}$, and infection-associated $\mathrm{AKI}$ has been associated with higher severity of illness, longer hospital stays, and increased mortality among hospitalized patients. ${ }^{1-3}$ Like other viral respiratory infections such as influenza, ${ }^{4,5}$ many patients with COVID-19 develop AKI, and a recent systematic review and meta-analysis of $A K I$ in COVID-19 found the incidence of AKI in this setting to be $12.3 \% .^{6}$ Acute kidney injury in the setting of COVID-19 frequently develops during the second week of infection. ${ }^{7}$

The causes of COVID-19-associated AKI are likely multifactorial, and are thought to include direct viral injury to kidney cells, dehydration, sepsis-mediated hypotension or immunologic injury, and microvascular disease. ${ }^{8,9}$ Care of patients with COVID-19 should include screening for AKI, prevention of $\mathrm{AKI}$ development or worsening, and treatment of $\mathrm{AKI}$, including treatment of renal failure. Each of these important clinical components can be challenging, as clinicians seek to balance the risks and benefits of treatments such as fluid resuscitation, antiviral medications, antibiotics for bacterial superinfection, and anti-inflammatory medications. These challenges are further impacted by limited human and physical resources. Here, we review the current literature on prevention, detection, and treatment of $\mathrm{AKI}$

*Address correspondence to Kristina E. Rudd, Department of Critical Care Medicine University of Pittsburgh School of Medicine 3520 5th Ave., Suite 100, Pittsburgh, PA 15261. E-mail: ruddk@pitt.edu among patients with COVID-19 in low- and middle-income countries (LMICs).

\section{METHODS}

A full description of the methods is provided in the Appendix. In brief, we formulated a set of questions regarding AKI for patients with suspected or confirmed COVID-19 in LMICs. The list of questions was reviewed for content and clarity by other members of the COVID-LMIC Task Force. After approval, the AKI subgroup assigned one member to search the literature for evidence to answer each question. The literature search was performed in PubMed and OVID, including articles pertaining to COVID-19, other respiratory viruses, and infection-related AKI. We selected relevant publications, appraised the evidence, and classified the quality of evidence as high, moderate, low, or very low. Recommendations were rated as strong or weak, depending on the quality of evidence and several other factors such as availability, affordability, and feasibility in LMICs. A strong recommendation was worded as "we recommend..." and a weak recommendation as "we suggest. ..," followed by the quality of evidence. The recommendations were reviewed by the $\mathrm{AKI}$ subgroup in an iterative process and were later reviewed by the entire task force in two rounds.

\section{QUESTIONS}

We formulated four clearly defined questions regarding $\mathrm{AKI}$ :

1. In patients with COVID-19 in LMICs, what are the available strategies to prevent AKI?

2. How should AKI be diagnosed in COVID-19 patients in LMICs? 
3. How should AKI be treated among COVID-19 patients in LMICs who do not require renal replacement therapy (RRT)?

4. In patients with COVID-19-related AKI in LMICs, what strategies can be used to optimize efficiency and availability of dialysis?

These questions and recommendations are discussed below.

Question 1: In patients with COVID-19 in LMICs, what are the available strategies to prevent AKI? Rationale. It remains unclear how $\mathrm{AKI}$ can best be prevented in patients with COVID-19. Understanding of the pathophysiology of COVID-19-related AKI is evolving, and approaches to prevention of COVID-19-related AKI will depend on this knowledge. ${ }^{8-11}$ Several mechanisms for AKI in the setting of COVID-19 have been suggested, including endothelial dysfunction, cardiogenic or vasodilatory shock, hypovolemia, cytokine storm, hypercoagulability causing microthrombi or infarction, direct cellular injury via angiotensin-converting enzyme 2 receptor-mediated acute tubular necrosis (ATN), or damage secondary to nephrotoxic drugs. ${ }^{10,12,13}$ Currently, most preventive measures for AKI in COVID-19 patients are based on the literature on AKI in the context of infection and acute hypoxemic respiratory failure. ${ }^{12,14}$

Search results. PubMed and OVID were searched through August 14, 2020 using combinations of MeSH terms and freetext words. A search for "acute kidney failure," "COVID-19/ SARS CoV-2," "prevention," and "developing countries" or MeSH terms mapping to these terms produced no results. Similarly, a search for "acute kidney failure," "low-income countries," and "COVID-19/SARS CoV-2" with mapping terms produced no results, and a search for "acute kidney failure," "developing countries," and "COVID-19" with mapping terms and free text did not produce any results. Broadening the search to "acute kidney failure" and "developing countries" produced 19 results and "acute kidney failure" and "low-income countries" produced 13 results. One study appeared in both searches. Of the 31 studies, seven studies were eliminated based on abstracts because of irrelevance. Of the remaining 24 studies, four studies had the same heading (one article published simultaneously in multiple journals). Of the remaining 21 studies, eight were reviews, three were systematic reviews or meta-analyses, two prospective and two retrospective observational studies, three comments, two research agendas (modified Delphi method), and one crosssectional study. No studies specifically discussed COVID19-associated AKI.

A search using the terms "acute kidney failure," "COVID-19/ SARS CoV-2," and "prevention" found 11 results. Broadening the search to "acute kidney failure" and "COVID-19/SARS CoV-2" produced 71 results on PubMed, of which nine were not in the English language. After removal of non-English studies, 62 studies remained. Of these, nine were eliminated after abstract screening. The remaining 53 studies included 10 reviews, six systematic reviews, 10 retrospective observational studies, one prospective observational study, 15 comments/letters, three clinical trials, two guidelines, and six case reports/case series. None were exclusively from an LMIC origin. An additional 22 relevant studies were identified after reference review.

Evidence. Given the absence of specific data on AKI prevention in the setting of COVID-19, we here review the general literature on prevention of infection-associated AKI. The Kidney Disease: Improving Global Outcomes (KDIGO) guidelines, published in 2012, recommend the implementation of a bundle of supportive measures in patients at high risk for AKI. ${ }^{15}$ Key elements included in this bundle are close monitoring of serum creatinine and urine output, optimization of hemodynamic parameters and volume status, establishment of functional hemodynamic monitoring, discontinuation of all nephrotoxic agents, avoidance of hyperglycemia, and consideration of alternatives to radiocontrast agents.

Volume depletion is a widely known cause of AKI, yet studies are lacking to compare the renal effects of early liberal versus conservative fluid resuscitation strategies in the setting of COVID-19. Most guidelines suggest targeting euvolemia, as the administration of fluids in the setting of initial hypovolemia (often secondary to increased insensible losses due to fever and increased respiratory effort) is thought to be protective, although fluid overload has been shown to increase mortality. ${ }^{16-18}$ A large randomized controlled trial showed that a conservative strategy of fluid management improved lung function and shortened the duration of mechanical ventilation and intensive care in patients with acute respiratory distress syndrome (ARDS) without increasing nonpulmonary organ failure. ${ }^{19}$ It has also been shown that patients with net positive fluid balance after an episode of AKI have worse outcomes. ${ }^{20}$ Studies comparing the difference between use of crystalloids versus colloids for fluid resuscitation have found that although albumin is safe to use, it is not more effective than crystalloids. ${ }^{21}$ Hydroxyethyl starch (HES) is sometimes used to treat hypovolemia, but studies have shown that hyperoncotic starches such as HES are associated with increased risk of AKI and mortality. ${ }^{22}$

One of the most effective methods of preventing AKI is the avoidance of nephrotoxic agents. Nephrotoxic agents are the third most common cause of $\mathrm{AKI}$ in intensive care units, and the list of potentially nephrotoxic agents is extensive. ${ }^{23} \mathrm{Al}-$ though the exact mechanism of AKI in the setting of COVID-19 is unclear, it is important to note that nephrotoxic agents can have additive or synergistic effects with respect to toxicity, ${ }^{23}$ and therefore may worsen the AKI caused by COVID-19. Implementation of the KDIGO supportive care guidelines, ${ }^{24}$ especially those regarding avoidance of nephrotoxic agents, is likely to reduce the occurrence and severity of AKI in COVID$19 .{ }^{25}$ Daily review of the necessity of medicines that can cause or worsen AKI is prudent, and their cessation is warranted unless use is essential. $^{26}$

The use of diuretics in the management of $\mathrm{AKI}$ is not recommended, although data specific to COVID-19 are lacking. The National Institute for Health and Care Excellence guidelines on COVID-19-related AKI stress that euvolemia should be the aim and that it is important to be aware that strategies to optimize ventilation management, such as diuretics, will put patients at risk for $\mathrm{AKI}^{26} \mathrm{~A} 2019$ review of the use of loop diuretics in AKI prevention and treatment concluded that loop diuretics are not beneficial for AKI treatment, and their use for AKI prevention can be associated with favorable outcomes only if euvolemia is preserved. ${ }^{27}$

Availability, feasibility, affordability, and safety. Most strategies recommended by KDIGO are of low cost, but availability and feasibility are suboptimal in some resource-limited settings because of insufficient supplies. ${ }^{15}$ Isotonic crystalloids are generally readily available in LMICs. A survey of 66 
intensive care facilities in the Democratic Republic of the Congo reported that crystalloids were available in $100 \%$ of units. ${ }^{28}$ Costs for IV crystalloids vary, although are generally low. One source reports the cost of $0.9 \%$ saline to be approximately US\$1/L, and that of Ringer's Lactate to be US\$1.10/L on average. ${ }^{29}$ The role of $5 \%$ human albumin in volume resuscitation is still debated, but the most relevant drawback for use in LMIC settings is its high cost, which is reported as US\$0.22-\$0.78/mL. ${ }^{30,31}$ A single-center Indonesian study evaluated the cost effectiveness of crystalloids and a crystalloid and colloid combination for the resuscitation of individuals with dengue fever, and found a $9 \%$ higher mean cost of hospitalization in those who received a crystalloid and colloid combination. $^{32}$

While achieving euvolemia in the early resuscitation of patients with infection is recommended to prevent AKI, how to achieve euvolemia safely and effectively in all clinical settings remains unclear. Several randomized clinical trials in LMICs have demonstrated harm from aggressive early resuscitation with both crystalloids and colloids. ${ }^{33,34}$ Further research remains to be carried out to establish the safest and most feasible approaches to resuscitation in LMICs.

Recommendations and suggestions (Table 1).

1. In patients with COVID-19 in LMICs, we recommend using isotonic crystalloid solutions rather than colloids for expansion of intravascular volume (strong recommendation, moderate quality of evidence).

2. In patients with COVID-19-related respiratory failure and $A K I$ in $\mathrm{LMICs}$, we recommend the use of a conservative fluid management strategy (strong recommendation, moderate quality of evidence).

3. In patients with COVID-19 in LMICs, we suggest the avoidance or cessation of nephrotoxic drugs when their use is not essential (moderate recommendation, weak quality of evidence).

Question 2: How should AKI be diagnosed in COVID-19 patients in LMICs? Rationale. Diagnosis of AKI in resourcelimited settings can be challenging. Previous research has found that, relative to high-income country (HIC) settings, patients in some LMIC settings experience delayed identification of infection-associated AKI, higher serum creatinine levels on AKI recognition, and later initiation of dialysis. ${ }^{1,35,36}$ In the setting of COVID-19, the diagnostic need has become more urgent, given the reported high prevalence of $\mathrm{AKI}$ in patients with COVID-19, as well as associations between AKI and increased in-hospital mortality among these patients. ${ }^{37}$

Search results. A search in PubMed through August 17, 2020 for "acute kidney failure," "COVID-19," and "resourcelimited" or MeSH terms mapping to these the terms yielded one result which was eliminated because of irrelevance. A search for "acute kidney failure," "COVID-19," and "LMICs" yielded no results, as did a search for "acute kidney failure," "COVID-19," and "low-resource settings." A search for "acute kidney failure" and "LMICs" yielded nine results, "acute kidney failure" and "low-resource settings" yielded 28 results, and "acute kidney failure" and "resource-limited" yielded 43 results on PubMed. Four studies appeared in two searches, and one study had the same heading. Of the 75 studies, 58 were eliminated because of irrelevance. Of the remaining 17 studies, there were four retrospective observational studies, four prospective observational studies, three surveys, one literature review, one consensus recommendation report, one cross-sectional study, and three case reports. An additional 11 studies were identified on examination of the references and "similar articles" section from the initial 17 studies. There were four literature reviews, four prospective observational studies, one retrospective observational study, and two cross-sectional studies. Additional studies of interest were those based in LMICs that identified the diagnostic methods used to identify $\mathrm{AKI}$ in completing the study.

A search "AKI diagnosis" and "low-resource settings" yielded 13 results, and a search for "AKI diagnosis" and "resource-limited" yielded five results. All studies had already appeared in a previous search. A search for "AKI diagnosis" and "resource-limited" yielded 18 results. Fourteen studies appeared in a previous search, and the remaining four were eliminated because of irrelevance. A search for "point-of-care (POC) creatinine" and "low-resource settings" yielded four results. One search study appeared in an earlier search, and two were eliminated because of irrelevance. The remaining study was a cross-sectional study. A search for "point-of care," creatinine," and "cost" yield 65 results, only two of which were relevant and pertaining to LMICs. One appeared in a previous search. The second was a comparative cost analysis. One additional cross-sectional study was identified in the reference section of these search results.

All included studies were either based in LMICs, or were multinational studies that included data collected from LMICs. All literature reviews referenced AKI in LMICs. No specific studies about AKI in COVID-19 patients in LMICs were found.

Evidence. Acute kidney injury diagnostic capabilities vary widely in LMICs. Although not available in all low-resource settings, serum creatinine laboratory values are the most commonly used tools to identify AKI. ${ }^{1,35,38-50}$ A 2015 multinational cross-sectional study showed that the diagnosis of AKI was made with serum creatinine values alone in $63 \%$ of participating facilities, followed by serum creatinine along with urine output in $28 \%$ of participating facilities in LMICs. ${ }^{1}$ A2018 qualitative study surveying $\mathrm{AKI}$ identification and management practices among 160 intensivists based in provincial and regional hospitals in Thailand showed that the KDIGO criteria for AKI were most commonly used (37\%), followed by the AKIN (27.7\%) and RIFLE (26.1\%) criteria, respectively. ${ }^{45} \mathrm{~A}$ common challenge with the use of serum creatinine values to diagnose $\mathrm{AKI}$ is the lack of historical laboratory values for many patients presenting with elevated serum creatinine due to the lack of electronic health record infrastructure in LMICs, leading to a delay in AKI diagnosis. ${ }^{35,51}$ One published consensus recommendation focused on LMICs suggests addressing this problem by treating any elevated serum creatinine in a patient as AKI until proven otherwise. ${ }^{51}$

Other AKI diagnostic and assessment tools most commonly used in LMICs include urinalysis, renal ultrasound, and renal biopsy. ${ }^{52}$ In two cross-sectional studies, these tools were shown to be used in $>70 \%$, approx. $50 \%$, and $4 \%$ of patients diagnosed with AKI in LMIC facilities, respectively. ${ }^{1,45}$ Multiple studies have shown that there is a higher incidence of proteinuria in patients with COVID-19 and AKI, relative to those with COVID-19 and no AKI, with incidence in AKI ranging from $42 \%$ to $83 \% .^{53-55}$ Given its excellent availability in LMICs, urinalysis may currently be one of the most feasible ways to identify AKI in patients with COVID-19 in LMICs. Salivary urea nitrogen dipstick test utilization has also proven 
TABLE 1

Recommendations and suggestions for the prevention and care of AKI among patients with COVID-19 in LMICs

\begin{tabular}{|c|c|c|}
\hline 1 & Prevention of AKI & $\begin{array}{l}\text { In patients with COVID-19 in LMICs, we recommend using isotonic } \\
\text { crystalloid solutions rather than colloids for expansion of intravascular } \\
\text { volume (strong recommendation, moderate quality of evidence). }\end{array}$ \\
\hline 1 & Prevention of AKI & $\begin{array}{l}\text { In patients with COVID-19-related respiratory failure and AKI in LMICs, we } \\
\text { recommend the use of a conservative fluid management strategy } \\
\text { (strong recommendation, moderate quality of evidence). }\end{array}$ \\
\hline 1 & Prevention of AKI & $\begin{array}{l}\text { In patients with COVID-19 in LMICs, we suggest the avoidance or } \\
\text { cessation of nephrotoxic drugs when their use is not essential } \\
\text { (moderate recommendation, weak quality of evidence). }\end{array}$ \\
\hline 2 & Diagnosis of $\mathrm{AKI}$ & $\begin{array}{l}\text { We suggest that any patient with COVID-19 presenting with an elevated } \\
\text { serum creatinine level without available historical values be considered } \\
\text { as having AKI until proven otherwise to prevent treatment delay (weak } \\
\text { recommendation, very low quality of evidence). }\end{array}$ \\
\hline 2 & Diagnosis of AKI & $\begin{array}{l}\text { In the absence of ability to test serum creatinine, we suggest the use of } \\
\text { urinalysis in patients with COVID-19 to identify proteinuria. Patients } \\
\text { with proteinuria should be considered as having possible AKI until } \\
\text { proven otherwise, to prevent treatment delay (weak recommendation, } \\
\text { very low quality of evidence). }\end{array}$ \\
\hline 2 & Diagnosis of $\mathrm{AKI}$ & $\begin{array}{l}\text { We suggest the expansion of the use of point-of-care serum creatinine } \\
\text { and salivary urea nitrogen testing in community health settings, as } \\
\text { funding and availability allow (weak recommendation, low quality of } \\
\text { evidence). }\end{array}$ \\
\hline 2 & Diagnosis of AKI & $\begin{array}{l}\text { We suggest the implementation of AKI awareness and training initiatives } \\
\text { among all levels of healthcare providers. Provider education should } \\
\text { ideally include education on the prevalence of AKI in COVID-19 patients } \\
\text { in addition to training on the presentation and diagnosis of AKI using } \\
\text { available resources at individual healthcare facilities (ungraded, best } \\
\text { practice statement). }\end{array}$ \\
\hline 3 & AKI treatment, non-dialysis & $\begin{array}{l}\text { We recommend the judicious use of intravenous fluid resuscitation using } \\
\text { crystalloids for early management of AKI in all COVID-19 patients } \\
\text { (strong recommendation, low quality of evidence). }\end{array}$ \\
\hline 3 & AKI treatment, non-dialysis & $\begin{array}{l}\text { We recommend more conservative fluid management for critically ill } \\
\text { COVID-19 patients. Negative fluid balance should be maintained, if } \\
\text { possible (strong recommendation, low quality of evidence). }\end{array}$ \\
\hline 3 & AKI treatment, non-dialysis & $\begin{array}{l}\text { We suggest the use of lung-protective mechanical ventilation strategies, } \\
\text { where applicable, to prevent renal injury from associated cytokine } \\
\text { release (weak recommendation, very low quality of evidence). }\end{array}$ \\
\hline 4 & AKI treatment, dialysis & $\begin{array}{l}\text { For AKI patients in LMICs with COVID-19 and no ARDS, we suggest using } \\
\text { PD as first choice, where available and feasible (weak recommendation, } \\
\text { low quality of evidence). }\end{array}$ \\
\hline 4 & AKI treatment, dialysis & $\begin{array}{l}\text { For AKI patients in LMICs with COVID-19 and ARDS, we suggest using } \\
\text { hemodialysis, where available and feasible, to optimize fluid removal } \\
\text { (weak recommendation, low quality of evidence). }\end{array}$ \\
\hline 4 & AKI treatment, dialysis & $\begin{array}{l}\text { We suggest using locally produced PD solutions when commercially- } \\
\text { produced solutions are unavailable or unaffordable (weak } \\
\text { recommendation, low quality of evidence). }\end{array}$ \\
\hline
\end{tabular}

AKI = acute kidney injury; ARDS = acute respiratory distress syndrome; LMICs = low- and middle-income countries; PD = peritoneal dialysis. Grading: See Appendix for detail.

to be an inexpensive and effective diagnostic test for $\mathrm{AKI}$ in sub-Saharan Africa with good specificity and sensitivity. ${ }^{56-58}$ Other devices for measuring creatinine that do not require refrigeration are also being investigated. ${ }^{59,60}$

Availability, feasibility, affordability, and safety. Availability of these diagnostic resources widely varies by practice location. A 2016 study surveyed 160 healthcare workers providing kidney care in low-resource settings around the world to evaluate resource availability for AKI diagnosis and management. ${ }^{61}$ In rural health centers, $84 \%$ of respondents stated that $\mathrm{AKI}$ diagnosis was made mostly based on clinical judgment, suggesting a lack of access to diagnostic tools in these settings. Only $63 \%$ and $85 \%$ of providers reported sufficient laboratory support for AKI diagnosis in district- and regionallevel hospitals, respectively. ${ }^{61}$ Practice location also affects personnel availability. In community and rural settings, physicians are often unavailable. First contacts with the healthcare system are often made through allied health professionals, nurses, and other community health leaders, who may have less working knowledge about AKI. ${ }^{1,62,63}$ The lack of both nephrology services and AKI awareness among community providers in low-resource settings can lead to delayed diagnosis. ${ }^{64,65}$

Improved $\mathrm{AKI}$ diagnosis heavily relies on both personnel and laboratory resource expansion in LMICs. Therefore, feasibility and affordability will vary by practice location. For example, expansion of POC serum creatinine testing, a relatively affordable diagnostic tool, could facilitate earlier AKI identification in the community setting and expedite time to treatment; however, the proper and safe use of $\mathrm{POC}$ testing requires access to electricity, specific storage conditions, trained personnel, and expensive calibration equipment. ${ }^{66-68}$ A 2019 comparative cost analysis of clinic-based POC versus centralized laboratory-based testing to monitor HIV treatment in South Africa found clinic-based POC testing to be more expensive than centralized laboratorybased creatinine testing, costing USD $\$ 9$ per patient versus $\$ 3 /$ patient. $^{69}$ Despite the higher cost per patient, POC creatinine testing might still be more immediately feasible in some settings, 
as expansion of centralized laboratory testing capabilities would require more resources, infrastructure, and up-front costs. In addition, the use of POC creatinine testing has already proven feasible in some cross-sectional studies from LMICs. ${ }^{68,70}$

Overarching healthcare provider training initiatives may be the most feasible and affordable first step, although implementation of efforts to improve AKI diagnostic capabilities should be adapted based on local infrastructure, cultural beliefs, and current facility capabilities to be most effective.

Recommendations and suggestions.

1. We suggest that any patient with COVID-19 presenting with an elevated serum creatinine level without available historical values be considered as having AKI until proven otherwise to prevent treatment delay (weak recommendation, very low quality of evidence).

2 . In the absence of ability to test serum creatinine, we suggest the use of urinalysis in patients with COVID-19 to identify proteinuria. Patients with proteinuria should be considered as having possible AKI until proven otherwise, to prevent treatment delay (weak recommendation, very low quality of evidence).

3. We suggest the expansion of the use of POC serum creatinine and salivary urea nitrogen testing in community health settings, as funding and availability allow (weak recommendation, low quality of evidence).

4. We suggest the implementation of AKI awareness and training initiatives among all levels of healthcare providers. Provider education should ideally include education on the prevalence of AKI in COVID-19 patients in addition to training on the presentation and diagnosis of AKI using available resources at individual healthcare facilities (ungraded, best practice statement).

Question 3: How should AKI be treated among COVID19 patients in LMICs who do not require RRT? Rationale. Treatment of $\mathrm{AKI}$ poses unique and widely varying challenges in LMICs. As studies emerge noting high prevalence of $\mathrm{AKI}$ in COVID-19 patients, as well as associations between AKI and in-hospital mortality in this population, further assessment of resources available to treat $\mathrm{AKI}$ in these settings is crucial. ${ }^{37}$

Search results. A search in PubMed for "AKI" and "COVID19 " or MeSH terms mapping to these terms yielded 76 results. One non-English study was eliminated, as were 59 other irrelevant studies. Of the remaining 16 results, 12 were literature reviews, one was an observational study, one was a systematic review, and two were practice guidelines. Further exploration of the references of these results yielded five additional studies. Three were retrospective observational studies, and two were case reports. Five additional relevant studies were discovered using these search terms on Google Scholar; of these, three were retrospective observational studies and two were case reports. Studies of interest were selected based on the inclusion of data related to the pathophysiology, histopathology, or management of AKI in COVID-19 patients.

A title/abstract search on PubMed for "volume management" and "COVID-19" yielded two results. One was eliminated because of irrelevance, and the remaining study was a literature review. Exploration of the references and "similar articles" section associated with this study yielded 10 relevant studies. Four were literature reviews, three were prospective observational studies, one was a retrospective observational study, and one was a systematic review. Studies of interest were selected based on the inclusion of data related to fluid management in AKI or COVID-19, or similar conditions involving acute lung disease or sepsis.

Five relevant studies appearing in search results for other questions in the guidelines were also used. Two were literature reviews, two were prospective observational studies, and one was a cross-sectional study. All studies published before August 17, 2020 were included in this search. All COVID-19related $\mathrm{AKI}$ studies were based in HICs, as no literature regarding COVID-related AKI was found from LMICs. Three studies regarding volume management did include data from LMIC settings.

Evidence. Incidence of AKI in COVID-19 patients among studies from HICs ranges from $4.7 \%$ to $75 \% .^{25,53-55,71-73}$ The development of $\mathrm{AKI}$ in this population has been independently associated with old age, mechanical ventilation, ARDS, vasopressor dependence, chronic comorbidities, and increased mortality. ${ }^{53,54,71,72,74,75}$ Because of high incidence and contribution to poor outcomes, targeted management of $\mathrm{AKI}$ in COVID-19 patients is of great concern; however, the pathophysiology of $\mathrm{AKI}$ in these patients is still being elucidated. Studies to date suggest that the pathophysiology of this condition is likely multifactorial. ${ }^{76-78}$ Histopathology suggestive of ATN has been the most consistent finding across postmortem kidney biopsy reports of COVID-19 patients with AKI. ${ }^{25,79-83}$ The largest study of kidney biopsy results in patients with COVID-19 and AKI, enrolling 26 patients from one institution, noted ATN in every patient. ${ }^{79}$ This finding has been attributed to renal hypoperfusion, infection-related cytokine activity, and nephrotoxic drugs. Some postmortem kidney biopsy studies reported the presence of viral inclusions in biopsied cells, collapsing glomerulopathy, and renal capillary fibrin thrombi, suggesting other potential etiologies of AKI, such as direct viral infection of renal tissue and ischemia resulting from microthrombi caused by COVID-19-induced hypercoagulability. ${ }^{10,79,81,84,85}$ Other biopsy results have suggested cytokine-mediated kidney damage ${ }^{10}$; however, these findings are less consistent across studies.

As a result of a largely undifferentiated etiology for this condition, there is currently no protocolized management for AKI in the setting of COVID-19. Current recommendations focus on supportive care. Fluid management with crystalloids has been suggested to prevent renal hypoperfusion ${ }^{25,26,86-89}$; however, this intervention would need to be very closely monitored. Positive fluid balance has been associated with poorer outcomes in patients with acute lung injury and sepsis, whereas conservative fluid management has been shown to improve lung function and decreased ventilator and ICU days. ${ }^{19,87,90-93}$ Recommendations for the treatment of $\mathrm{AKI}$ in COVID-19 patients also include the reduction of barotrauma and volutrauma in mechanically ventilated patients to prevent further release of damaging cytokines. ${ }^{25}$

Availability, feasibility, affordability, and safety. Wide variation in healthcare infrastructure, staffing, and funding within and across LMICs results in a broad range of treatment capabilities. A 2015 cross-sectional study of the identification and management of $\mathrm{AKI}$ in various healthcare facilities showed that crystalloid fluid was used as initial management in $92 \%$ of all patients in LMICs. In addition, $73.9 \%$ of these patients were administered antibiotics. Diuretics were used in $36.1 \%$ of patients. ${ }^{1}$ A 2016 survey of 160 physicians treating kidney disease in low-resource settings found that nearly all 
regional hospitals had access to oral and intravenous hydration solutions, and antibiotics, whereas only $60 \%$ and $52 \%$ of rural healthcare providers had access to intravenous fluids and antibiotics for AKI management, respectively. ${ }^{61}$

Feasibility and affordability of AKI treatment has been an ongoing challenge in LMICs, especially in remote and community healthcare settings. Intravenous fluids are the most commonly available resource for the management of $\mathrm{AKI}$ in both urban and community settings in LMICs and could be used to the benefit of AKI patients early in their disease courses. However, emerging evidence indicating increased adverse outcomes among AKI, ARDS, and critically ill patients receiving excessive fluid resuscitation poses safety concerns if this treatment is improperly implemented by providers with little working knowledge of fluid management. ${ }^{89,92,94,95}$ One observational study of 1,808 patients with sepsis across ICUs in 84 countries found an increased risk of death in those with higher fluid balance. ${ }^{96}$ Multiple reviews regarding fluid management in the setting of COVID-19 therefore recommend maintaining a negative fluid balance to improve outcomes, especially in critically ill patients dependent on mechanical ventilation. $^{87,97}$

Recommendations and suggestions (Table 1).

1. We recommend the judicious use of intravenous fluid resuscitation using crystalloids for early management of AKI in all COVID-19 patients (strong recommendation, low quality of evidence).

2. We recommend more conservative fluid management for critically ill COVID-19 patients. Negative fluid balance should be maintained, if possible (strong recommendation, low quality of evidence).

3. We suggest the use of lung-protective mechanical ventilation strategies, where applicable, to prevent renal injury from associated cytokine release (weak recommendation, very low quality of evidence).

Question 4: In patients with COVID-19-related AKI in LMICs, what strategies can be used to optimize efficiency and availability of dialysis? Rationale. AKI secondary to COVID-19 is common, and is associated with increased mortality. ${ }^{98-100}$ A review of AKI in sub-Saharan Africa demonstrated significantly reduced mortality with the provision of dialysis. ${ }^{101}$ Unfortunately, dialysis for the treatment of $A K I$ is often scarce in LMICs because of limitations of equipment, human resources, and funding. Basic supplies, such as clean water and electricity, are also, at times, limited or unavailable. ${ }^{102}$ Improved efficiency and availability of dialysis is critical to optimize outcomes of patients with AKI and COVID-19 in LMICs.

Search results. PubMed was searched using the following terms, either as MeSH terms or as free-text words up to the date of August 14, 2020: "AKI," "resource-limited," "COVID," "lower-middle income countries," "low-resource settings," "underdeveloped countries," "RRT," "hemodialysis (HD)," "peritoneal dialysis (PD)," "cost-effectiveness," and "cost," "barriers," "efficiency." Forty studies were identified. Review of the references of these studies produced another six studies. A large majority of the studies identified were observational studies and reviews. Nearly half of all studies identified were randomized controlled trials or cost analysis and feasibility studies. Two systematic reviews were also identified. Studies regarding RRT options in both HICs and LMICs were included; 18 studies were based in LMICs.
Evidence. The need for dialysis is common among patients with AKI in LMICs. ${ }^{1,35,43,101}$ Dialysis for AKI is mostly available solely through regional healthcare facilities, ${ }^{61}$ and even in these settings, access is not consistent. Whereas some AKI studies from LMICs report that all study participants requiring dialysis received the treatment, other studies reported difficulties accessing this therapy. A 2015 study of outcomes among AKI patients in Uganda reported a $21 \%$ hospital mortality rate, with most deaths among patients whose conditions required $\mathrm{HD}$ or care in an ICU, both of which were resources not available at the treating facility. ${ }^{43}$ Another study investigating AKI outcomes in sub-Saharan Africa found that only $33 \%$ of adult patients in the study received dialysis when it was needed. ${ }^{101}$ Barriers to dialysis treatment, in addition to access, include financial limitations, as dialysis is often an outof-pocket patient expense. ${ }^{103-106}$ In LMIC facilities with available treatment, intermittent HD is the most available, with reported utilization of $69-95 \%$ when dialysis is required. ${ }^{1,45}$ Sustained low-efficiency dialysis (SLED) and PD were also used in facilities with dialysis capabilities. ${ }^{1,35}$

Provision of acute PD treatments is one practical approach to the management of AKI. ${ }^{106}$ The Oby25 initiative, developed by the International Society of Nephology (ISN), has placed focus on the importance of diagnosis and treatment of AKI, especially in LMICs. The Saving Young Lives program (a consortium of the ISN, International Society for PD, International Pediatric Nephrology Association, Euro-PD, and the Sustainable Kidney Care Foundation) has promoted the use of PD to treat AKI in LMICs. The program has endorsed the training of doctors and nurses, provided technical assistance, and helped to offset cost for PD supplies. ${ }^{107,108}$

Vasudevan et al. ${ }^{109}$ reported that even with the availability of PD, HD, continuous RRT, and SLED in 23 of the 26 centers surveyed in India, PD was the most preferred modality because of lower cost and simplicity. Furthermore, Abdou et al. report that $P D$ is the most commonly used $R R T$ modality in Africa. ${ }^{110}$ With respect to the use of PD in AKI, a recent randomized clinical trial in Brazil showed that outcomes were comparable with respect to metabolic control, infectious and mechanical complications, renal function recovery, patient survival, and mortality with the use of PD compared with HD in AKI. ${ }^{111}$ An earlier study conducted in eastern Nepal showed that nursing staff, technicians, and doctors can be easily trained in the use of PD for AKI. ${ }^{112}$ One systematic review of $\mathrm{AKI}$ in sub-Saharan Africa revealed that there was no mortality difference between children who received HD and those who received PD. ${ }^{101}$ Another systematic review performed in 2013 concluded that there is no significant difference in outcomes between PD and HD. ${ }^{113}$ Another study performed in Nigeria showed that that both PD and HD were comparably effective in the control of uremia, with significant reductions in serum urea, creatinine, and potassium levels. ${ }^{114}$

COVID-19-specific research for the management of AKI is still emerging. Many studies are reviews that explore the challenges of delivering RRT to patients with COVID-19. Although most of the reviews are focused on high-resource settings, they are important in the context of shortages of equipment and manpower in a pandemic, and therefore reflect practices that could be adapted in LMICs, where shortages are more common. Hemodialysis modalities used for AKI in COVID-19 have resulted in the observation that many of the COVID-19 patients have abnormalities of coagulation and 
repeated clotting of extracorporeal circuits, reflective of the hypercoagulability, and therefore that PD is a suitable alternative. Counter arguments state that because the primary manifestation of COVID-19 is respiratory in the form of ARDS, PD should not be the first choice in these patients where fluid removal may be necessary, as PD has limitations in that respect. ${ }^{115,116}$ One study that looked at the safety and efficacy of PD catheter placement in COVID-19 patients concluded that placement with a two-person team was feasible and that the need for the recommended break-in period of 2 weeks after PD catheter placement is safe to forego in acute settings. ${ }^{117}$ Currently, there are no data showing virus spread from PD effluent. A report published recently suggested this may be the case, but it was argued that it is not clear whether a positive PCR for SARS-CoV-2 means contagious virus is present, and there are no other cases reported. ${ }^{118} \mathrm{~A}$ review article published from South Africa on the use of PD in COVID19 patients with AKI summarizes the advantages and challenges faced with the use of PD. ${ }^{115}$ This review stresses one of the most important advantages of PD in COVID-19 as being that it requires a lower nursing ratio and less interventions by the nurse per session, thereby making it ideal for a scenario of a pandemic. Another letter stresses that because the timing of exchange of fluids for PD is controllable, it could be timed to coincide with other interventions for the patient. ${ }^{119}$ An editorial mentioning experience of AKI in COVID-19 mentions that a major advantage of PD during this pandemic has been the ability to train non-nursing staff in the PD procedure, which is safe and straightforward. ${ }^{120}$

Availability, feasibility, affordability, and safety. Availability of dialysis treatment in LMICs is highly variable. Cost may also be a challenge in expanding dialysis access. Although both HD and PD are commonly used in LMICs, PD has proven to be less costly, with one 2011 study finding that PD was half the cost of HD. ${ }^{121,122}$ In addition, PD requires less equipment, technology, and electricity to be implemented than HD, making it a more feasible treatment option in some rural or community settings. $^{123}$

In addition to the cost and infrastructure challenges in providing dialysis, the lack of trained personnel is also a barrier in many low-resource settings. ${ }^{123,124}$ Countries are addressing this shortage of providers in different ways. One study piloting a 5-week training program to increase healthcare provider aptitude in performing PD in Tanzania was successful in developing competency among trained nurses, allowing them to properly administer PD where resources were available. ${ }^{124}$

One of the most important barriers to dialysis treatment is high out-of-pocket expenses for patients. Some countries have successfully worked to address this challenge. For example, in 2007, Thailand implemented a universal coverage dialysis program, the "PD First" Policy, through which dialysis was reimbursed through the government instead of being paid out-of-pocket by patients requiring services. This increased utilization of PD over HD from less than 10-23.1\% in $2012 .{ }^{125}$ Physician partnership with government and nongovernmental organizations can potentially improve access to funding to make dialysis more affordable to patients. One study of the cost of provision of PD in Africa found that the minimum requirements for conducting guideline-based PD involves the following costs per day: fluid, ranging from US\$24-40; PD catheter ranging from US\$6.60-30, depending on whether it is a rigid or flexible catheter; and catheter insertion and care provided by healthcare providers. These last costs represent a relatively small proportion of the total overall cost. ${ }^{126}$ In Tanzania, the average cost per full PD treatment for an AKI case was US\$788, making it highly cost effective as per WHO categorization in this setting. ${ }^{126}$ In another study conducted in northern Tanzania, ${ }^{124}$ a follow-up analysis of the cost of acute PD per case treated (variable number of days of dialysis required) was performed. A comparison using subsidized cost versus cost based on market price was performed based on 14 cases. The average cost per AKI course of treatment with PD when subsidized was US $\$ 420$, whereas the same treatment, if privately procured, was US\$788. ${ }^{126}$ Likewise, Obiagwa and Abdu showed that PD was particularly cheaper in children than HD. ${ }^{127}$

By contrast, one study found that in countries such as India, Brazil, Nigeria, and South Africa, the cost of HD and PD treatments are roughly the same. ${ }^{128}$ This study, however, included the annual PD and HD costs for chronic kidney disease. Therefore, the analysis does not reflect the costs associated with $\mathrm{AKI}$ alone.

Given the cost and logistical difficulties of procuring commercially prepared dialysis solutions, one center in South Africa has reported their experience using locally produced PD solutions using intravenous fluids. ${ }^{129}$ They found a $4 \%$ incidence of peritonitis (2/49 patients) and no cases of electrolyte disturbances secondary to the PD. Multiple other studies conclude that as the use of PD becomes more common, more local solutions will be produced. ${ }^{130}$ One study which compared the use of locally produced PD solution with commercially produced PD solutions found peritonitis occurred in $16 \%$ of patients treated with the local solutions, identical to the percentage seen with commercially made solution. ${ }^{131}$

Recommendations and suggestions (Table 1).

1. For AKI patients in LMICs with COVID-19 and no ARDS, we suggest using $P D$ as first choice, where available and feasible (weak recommendation, low quality of evidence).

2. For AKI patients in LMICs with COVID-19 and ARDS, we suggest using $\mathrm{HD}$, where available and feasible, to optimize fluid removal (weak recommendation, low quality of evidence).

3. We suggest using locally produced PD solutions when commercially produced solutions are unavailable or unaffordable (weak recommendation, low quality of evidence).

Received September 21, 2020. Accepted for publication December 21, 2020.

Published online January 11, 2021.

Note: The Appendix can be found at www.ajtmh.org.

Financial support: Open access fees for this article and all others in this issue were supported by the Wellcome Trust of Great Britain.

Authors' addresses: Kristina E. Rudd, Department of Critical Care Medicine, University of Pittsburgh, Pittsburgh, PA, E-mail: ruddk@pitt.edu. ElifA. Cizmeci, Interdepartmental Division of Critical Care Medicine, University of Toronto, Toronto, Canada, E-mail: eacizmeci@gmail.com. Gabriela M. Galli, School of Medicine, University of Pittsburgh, Pittsburgh, PA, E-mail: galli.gabriela@medstudent.pitt.edu. Ganbold Lundeg, Department of Critical Care and Anaesthesia, Mongolian National University of Medical Sciences, Ulaanbaatar, Mongolia, E-mail: ganbold.Iun@ gmail.com. Marcus J. Schultz, Department of Intensive Care, Amsterdam University Medical Centers, Amsterdam, The Netherlands, Mahidol-Oxford Tropical Medicine Research Unit (MORU), 
Mahidol University, Bangkok, Thailand, and Nuffield Department of Medicine, Oxford University, Oxford, United Kingdom, E-mail: marcus.j.schultz@gmail.com. Alfred Papali, Division of Pulmonary and Critical Care Medicine, Atrium Health, Charlotte, NC, E-mail: alfred.papali@atriumhealth.org.

This is an open-access article distributed under the terms of the Creative Commons Attribution (CC-BY) License, which permits unrestricted use, distribution, and reproduction in any medium, provided the original author and source are credited.

\section{GROUP MEMBERS OF THE "COVID-LMIC TASK FORCE"}

Heads: Alfred Papali (Atrium Health, Charlotte, NC) and Marcus Schultz (Mahidol University, Bangkok, Thailand; University of Oxford, Oxford, United Kingdom; Amsterdam University Medical Centers, location "AMC," Amsterdam, The Netherlands).

Advisors: Neill K. J. Adhikari (Interdepartmental Division of Critical Care Medicine, University of Toronto, Toronto, Canada); Emilie J. Calvello Hynes (University of Colorado School of Medicine, Department of Emergency Medicine, Denver); Martin Dünser (Kepler University Hospital and Johannes Kepler University Linz, Linz, Austria); and Mervyn Mer (University of the Witwatersrand, Johannesburg, South Africa).

Subgroup members, in alphabetical order: Andrew Achilleos (Sunnybrook Health Sciences Centre, Toronto, Canada); Hanan Y. Ahmed (Department of Internal Medicine, College of Health Sciences, Addis Ababa University, Addis Ababa, Ethiopia); Kevan M. Akrami (Universidade Federal da Bahia, Faculdade de Medicina, Salvador, Brazil and Division of Infectious Disease, Department of Medicine, University of California San Diego, San Diego, CA); Lia M. Barros (University of Washington, Seattle, WA); B. Jason Brotherton (AIC Kijabe Hospital, Kijabe, Kenya); Sopheakmoniroth Chea (Calmette Hospital, Phnom Penh, Cambodia); William Checkley (The Johns Hopkins University School of Medicine and The Johns Hopkins University Center for Global Health, Baltimore, MD); Elif A. Cizmeci (Interdepartmental Division of Critical Care Medicine, Sunnybrook Health Sciences Centre, University of Toronto, Toronto, Canada); Natalie Cobb (University of Washington, Seattle, WA); Finot Debebe (Department of Emergency Medicine and Critical Care, Addis Ababa University School of Medicine, Addis Ababa, Ethiopia); Juliana Ferreira (University of São Paulo, São Paulo, Brasil); Gabriela Galli (University of Pittsburgh School of Medicine, Pittsburgh, PA); Tewodros Haile (Department of Internal Medicine, College of Health Sciences, Addis Ababa University); Bhakti Hansoti (Department of Emergency Medicine, Johns Hopkins University School of Medicine, Baltimore, MD); Madiha Hashmi (Ziauddin University, Karachi, Pakistan); Rebecca Inglis (Lao-Oxford-Mahosot Hospital-Wellcome Trust Research Unit (LOMWRU), Mahosot Hospital, Vientiane, Lao People's Democratic Republic and Department of Intensive Care, Oxford University Hospital Trust, Oxford, United Kingdom); Burton W. Lee (University of Pittsburgh, Pittsburgh, PA); Faith Lelei (AIC Kijabe Hospital, Kijabe, Kenya); Ganbold Lundeg (Mongolian National University of Medical Sciences, Ulan Bator, Mongolia); David Misango (The Aga Khan University, Nairobi, Kenya); Ary Serpa Neto (Department of Critical Care Medicine, Hospital Israelita Albert Einstein, São Paulo, Brazil; Australian and New Zealand Intensive Care Research Center (ANZIC-RC), Monash University, Melbourne, Australia; Department of Intensive Care, Amsterdam University Medical Centers, location "AMC," University of Amsterdam, Amsterdam, The Netherlands); Alfred Papali (Atrium Health, Charlotte, NC); Casey Park (Interdepartmental Division of Critical Care Medicine, Sunnybrook Health Sciences Centre, University of Toronto, Toronto, Canada); Rajyabardhan Pattnaik (Ispat General Hospital, Rourkela, India); Luigi Pisani (Department of Anesthesia and Intensive Care, Miulli Regional Hospital, Acquaviva delle Fonti, Italy; Doctors with Africa-CUAMM, Padova, Italy; Mahidol-Oxford Tropical Medicine Research Unit (MORU), Mahidol University, Bangkok, Thailand); Elisabeth D. Riviello (Division of Pulmonary, Critical Care, and Sleep Medicine, Beth Israel Deaconess Medical Center and Harvard Medical School, Boston); Kristina E. Rudd (University of Pittsburgh School of Medicine, Pittsburgh, PA); Marcus Schultz (Mahidol University, Bangkok, Thailand; University of Oxford, Oxford, United Kingdom; Amsterdam University Medical Centers, location 'AMC,' Amsterdam, The Netherlands); Varun U. Shetty (University of Pittsburgh Medical Center, Pittsburgh, USA); Gentle S. Shrestha (Tribhuvan University Teaching Hospital,
Kathmandu, Nepal); Chaisith Sivakorn (Mahidol University, Salaya, Thailand); Shaurya Taran (Interdepartmental Division of Critical Care Medicine, Sunnybrook Health Sciences Centre, University of Toronto, Toronto, Canada); T. Eoin West (University of Washington, Seattle, WA).

Group members of the subgroup "Acute Kidney Injury": Kristina E. Rudd (University of Pittsburgh, Pittsburgh, PA); Elif A. Cizmeci (University of Toronto, Toronto, Canada); Gabriela M. Galli (University of Pittsburgh, Pittsburgh, PA); Ganbold Lundeg (Mongolian National University of Medical Sciences, Ulaanbaatar, Mongolia); Marcus J. Schultz (Amsterdam University Medical Centers, Amsterdam, The Netherlands; Mahidol University, Bangkok, Thailand; Oxford University, Oxford, United Kingdom); and Alfred Papali (Atrium Health, Charlotte, NC).

\section{REFERENCES}

1. Mehta RL et al., 2016. Recognition and management of acute kidney injury in the International Society of Nephrology 0 by25 Global Snapshot: a multinational cross-sectional study. Lancet 387: 2017-2025.

2. Alobaidi R, Basu RK, Goldstein SL, Magshaw SM, 2015. Sepsisassociated acute kidney injury. Semin Nephrol 35: 2-11.

3. Uchino $S$ et al., 2005. For the beginning and ending supportive therapy for the kidney (BEST kidney) investigators. Acute renal failure in critically ill patients: a multinational, multicenter study. J Am Med Assoc 294: 813-818.

4. Bagshaw SM, Sood MM, Long J, Fowler RA, Adhikari NKJ, 2013. Acute kidney injury among critically ill patients with pandemic H1N1 influenza A in Canada: cohort study. BMC Nephrol 14: 123.

5. Casas-Aparicio GA, León-Rodríguez I, De Jesuús HernándezZenteno R, Castillejos-López M, Alvarado-De La Barrera C, Ormsby CE, Reyes-Terán G, 2018. Aggressive fluid accumulation is associated with acute kidney injury and mortality in a cohort of patients with severe pneumonia caused by influenza $A$ H1N1 virus. PLoS One 13: 1-14.

6. Oliveira CB, Lima CAD, Vajgel G, Campos Coelho AV, SandrinGarcia P, 2020. High burden of acute kidney injury in COVID-19 pandemic: systematic review and meta-analysis. J Clin Pathol (Epub ahead of print 2020 Oct 6 jclinpath-2020-207023). doi: 10.1136/jclinpath-2020-207023.

7. Zhou F et al., 2020. Clinical course and risk factors for mortality of adult inpatients with COVID-19 in Wuhan, China: a retrospective cohort study. Lancet 395: 1054-1062.

8. Puelles VG et al., 2020. Multiorgan and renal tropism of SARSCoV-2. N Engl J Med 383: 590-592.

9. Sise ME, Baggett MV, Shepard JAO, Stevens JS, Rhee EP, 2020. Case 17-2020: a 68-year-old man with COVID-19 and acute kidney injury. N Engl J Med 382: 2147-2156.

10. Batlle D, Soler MJ, Sparks MA, Hiremath S, South AM, Welling PA, Swaminathan S; COVID-19 and ACE2 in Cardiovascular, Lung, and Kidney Working Group, 2020. Acute kidney injury in COVID-19: emerging evidence of a distinct pathophysiology. J Am Soc Nephrol 31: 1380-1383.

11. Soleimani $M, 2020$. Acute kidney injury in SARS-CoV-2 infection: direct effect of virus on kidney proximal tubule cells. Int $J \mathrm{Mol}$ Sci 21: 3275.

12. Ronco C, Reis T, Husain-Syed F, 2020. Management of acute kidney injury in patients with COVID-19. Lancet Respir Med 2019: 1-5.

13. Letko M, Marzi A, Munster V, 2020. Functional assessment of cell entry and receptor usage for SARS-CoV-2 and other lineage B betacoronaviruses. Nat Microbiol 5: 562-569.

14. Hassanein M, Thomas G, Taliercio J, 2020. Management of acute kidney injury in COVID-19. Cleve Clin J Med 286: 1-3.

15. Kidney Disease: Improving Global Outcomes (KDIGO) Acute Kidney Injury Work Group, 2012. KDIGO clinical practice guideline for acute kidney injury. Kidney Int Suppl 2: 1-138.

16. Ali TZ, Khan I, Simpson W, Prescott G, Townend J, Smith W, MacLeod A, 2007. Incidence and outcomes in acute kidney injury: a comprehensive population-based study. J Am Soc Nephrol 18: 1292-1298.

17. Bouchard J, Soroko SB, Chertow GM, Himmelfarb J, Ikizler TA, Paganini EP, Mehta RL, 2009. Fluid accumulation, survival and 
recovery of kidney function in critically ill patients with acute kidney injury. Kidney Int 76: 422-427.

18. Payen D, de Pont AC, Sakr Y, Spies C, Reinhart K, Vincent JL, 2008. A positive fluid balance is associated with a worse outcome in patients with acute renal failure. Crit Care 12: 1-7.

19. Wiedemann HP, Wheeler AP, Bernard GR, Thompson BT, Hayden D, DeBoisblanc B, Connors AF, Hite RD, Harabin AL, 2006. Comparison of two fluid-management strategies in acute lung injury. N Engl J Med 354: 2564-2575.

20. Grams ME, Estrella MM, Coresh J, Brower RG, Liu KD, 2011. Fluid balance, diuretic use, and mortality in acute kidney injury. Clin J Am Soc Nephrol 6: 966-973.

21. The SAFE Study Investigators, 2004. A comparison of albumin and saline for fluid resuscitation in the intensive care unit. $\mathrm{NEngl}$ J Med 350: 2247-2256.

22. Wiedermann CJ, Dunzendorfer S, Gaioni LU, Zaraca F, Joannidis M, 2010. Hyperoncotic colloids and acute kidney injury: a meta-analysis of randomized trials. Crit Care 14: 1-9.

23. Mas-Font S, Ros-Martinez J, Pérez-Calvo C, Villa-Díaz $P$, Aldunate-Calvo S, Moreno-Clari E, 2017. Prevention of acute kidney injury in intensive care units. Med Intensiva 41: 116-126.

24. Kellum JA, Lameire N; for the KDIGO Guideline Work Group, 2013. Diagnosis, evaluation, and management of acute kidney injury: a KDIGO summary (Part 1). Crit Care 17: 1-15.

25. Ronco C, Reis T, Husain-Syed F, 2020. Management of acute kidney injury in patients with COVID-19. Lancet Respir Med 8: 738-742.

26. Selby NM, Forni LG, Laing CM, Horne KL, Evans RDR, Lucas BJ, Fluck RJ, 2020. COVID-19 and acute kidney injury in hospital: summary of NICE guidelines. BMJ 369: m1963.

27. Patschan D, Patschan S, Buschmann I, Ritter O, 2019. Loop diuretics in acute kidney injury prevention, therapy, and risk stratification. Kidney Blood Press Res 44: 457-464.

28. Baelani I, Jochberger S, Laimer T, Rex C, Baker T, Wilson IH, Grander W, Dünser MW, 2012. Identifying resource needs for sepsis care and guideline implementation in the Democratic Republic of the Congo: a cluster survey of 66 hospitals in four eastern provinces. Middle East J Anesthesiol 21: 559-576.

29. Single Drug Information - International Medical Products Price Guide (n.d.). Available at: https://mshpriceguide.org/en/singledrug-information/?DMFId=724\&searchYear=2014. Accessed May 27, 2020.

30. Vincent JL, Russell JA, Jacob M, Martin G, Guidet B, Wernerman J, Ferrer Roca R, McCluskey SA, Gattinoni L, 2014. Albumin administration in the acutely ill: what is new and where next? Crit Care 18: 1-10.

31. Albumin Solution: Drug Information-UpToDate (n.d.). Available at: https://www.uptodate.com/contents/albumin-solution-druginformation?search=albumin\&source=search_result\&selectedTitle= $\uparrow 150 \&$ usage type $=$ default\&display_rank=1\#F16322967. Accessed May 27, 2020.

32. Anggriani Y, Banun A, Sakit FR, Kefarmasian M, 2018. Cost effectiveness analysis of crystalloid and crystalloid-colloid combination on dengue fever without shock in Bhakti asih general hospital tangerang. J Manag Pharm Pract 8: 70-79.

33. Maitland $\mathrm{K}$ et al., 2011. Mortality after fluid bolus in African children with severe infection. N Engl J Med 364: 2483-2495.

34. Andrews B, Semler MW, Muchemwa L, Kelly P, Lakhi S, Heimburger DC, Mabula C, Bwalya M, Bernard GR, 2017. Effect of an early resuscitation protocol on in-hospital mortality among adults with sepsis and hypotension: a randomized clinical trial. JAMA 318: 1233-1240.

35. Bouchard J, Acharya A, Cerda J, Maccariello ER, Madarasu RC, Tolwani AJ, Liang X, Fu P, Liu ZH, Mehta RL, 2015. A prospective international multicenter study of $A K I$ in the intensive care unit. Clin J Am Soc Nephrol 10: 1324-1331.

36. Kaballo BG, Khogali MS, Khalifa EH, Khaiii EAG, Ei-Hassan AM, Abu-Aisha H, 2007. Patterns of "severe acute renal failure" in a referral center in Sudan: excluding intensive care and major surgery patients. Saudi J Kidney Dis Transpl 18: 220-225.

37. Cheng Y, Luo R, Wang K, Zhang M, Wang Z, Dong L, Li J, Yao Y, Ge S, Xu G, 2020. Kidney disease is associated with in-hospital death of patients with COVID-19. Kidney Int 97: 829-838.

38. Seedat F, Martinson N, Motlhaoleng K, Abraham P, Mancama D, Naicker S, Variava E, 2017. Acute kidney injury, risk factors, and prognosis in hospitalized HIV-infected adults in South Africa, compared by tenofovir exposure. AIDS Res Hum Retroviruses 33: $33-40$.

39. Aminde JA, Adze NE, Dedino GA, Aminde LN, 2019. Acute kidney injury as initial presentation of renal lymphoma: diagnostic and therapeutic challenges in a resource-limited setting. SAGE Open Med Case Rep 7: 2050313X19845251.

40. Ryakitimbo A, Kennedy M, Shao E, Itana ME, Mbwasi R, Kinabo G, Yeates K, Kilonzo K, 2018. Acute kidney injury in a Tanzanian boy following multiple bee stings in resource-limited setting: a case report. Oxford Med Case Rep 2018: 328-331.

41. Sukmark T, Lumlertgul N, Praditpornsilpa K, Tungsanga K, Eiam-Ong S, Srisawat N, 2020. SEA-MAKE score as a tool for predicting major adverse kidney events in critically ill patients with acute kidney injury: results from the SEA-AKI study. Ann Intensive Care 10: 42.

42. Evans RDR, Hemmilä U, Craik A, Mtekateka M, Hamilton F, Kawale Z, Kirwan CJ, Dobbie H, Dreyer G, 2017. Incidence, aetiology and outcome of community-acquired acute kidney injury in medical admissions in Malawi. BMC Nephrol 18: 1-9.

43. Bagasha $P$, Nakwagala F, Kwizera A, Ssekasanvu E, Kalyesubula R, 2015. Acute kidney injury among adult patients with sepsis in a low-income country: clinical patterns and shortterm outcomes. BMC Nephrol 16: 1-7.

44. Priyamvada P, Jayasurya R, Shankar V, Parameswaran S, 2018. Epidemiology and outcomes of acute kidney injury in critically ill: experience from a tertiary care center. Indian J Nephrol 28: 413-420.

45. Srisawat N, Sintawichai N, Kulvichit W, Lumlertgul N, Sitticharoenchai $\mathrm{P}$, Thamrongsat N, Peerapornratana S, 2018. Current practice of diagnosis and management of acute kidney injury in intensive care unit in resource limited settings. J Crit Care 46: 44-49.

46. Muhamedhussein MS, Ghosh S, Khanbhai K, Maganga E, Nagri Z, Manji M, 2019. Prevalence and factors associated with acute kidney injury among malaria patients in Dar es Salaam: a crosssectional study. Malar Res Treat 2019: 1-7.

47. Ribeiro Do Nascimento GV, Silva MDN, deCarvalho Neto JD, Feitosa Filho LR, Antão JD, 2020. Outcomes in acute kidney injury in noncritically ill patients lately referred to nephrologist in a developing country: a comparison of AKIN and KDIGO criteria. BMC Nephrol 21: 1-7.

48. Asinobi AO, Ademola AD, Alao MA, 2016. Haemodialysis for paediatric acute kidney injury in a low resource setting: experience from a tertiary hospital in South West Nigeria. Clin Kidney J 9: 63-68.

49. Masewu A et al., 2016. Acute kidney injury is a powerful independent predictor of mortality in critically ill patients: a multicenter prospective cohort study from Kinshasa, the Democratic Republic of Congo. BMC Nephrol 17: 1-7.

50. Okunola Y, Ayodele O, Akinwusi P, Gbadegesin B, Oluyombo R, 2013. Haemodialysis practice in a resource-limited setting in the tropics. Ghana Med J 47: 4-9.

51. Cerdá J, Mohan S, Garcia-Garcia G, Jha V, Samavedam S, Gowrishankar S, Bagga A, Chakravarthi R, Mehta R, 2017. Acute kidney injury recognition in low- and middle-income countries. Kidney Int Rep 2: 530-543.

52. Bouchard J, Mehta RL, 2016. Acute kidney injury in western countries. Kidney Dis 2: 103-110.

53. Hirsch JS et al., 2020. Acute kidney injury in patients hospitalized with COVID-19. Kidney Int 98: 209-218.

54. Lim JH et al., 2020. Fatal outcomes of COVID-19 in patients with severe acute kidney injury. J Clin Med 9: 1718.

55. Taher A, Alalwan AA, Naser N, Alsegai O, Alaradi A, 2020. Acute kidney injury in COVID-19 pneumonia: a single-center experience in Bahrain. Cureus 12: 1-14.

56. Calice-Silva V, Sacomboio E, Raimann JG, Evans R, Dos Santos Sebastião C, Tchivango AT, Kotanko P, Levin N, Pecoits-Filho $\mathrm{R}, 2018$. Diagnostic performance of salivary urea nitrogen dipstick to detect and monitor acute kidney disease in patients with malaria. Malar J 17: 1-8.

57. Evans $R$ et al., 2017. Diagnostic performance of a saliva urea nitrogen dipstick to detect kidney disease in Malawi. Kidney Int Rep 2: 219-227.

58. Evans RDR et al., 2020. Diagnostic performance of a point-ofcare saliva urea nitrogen dipstick to screen for kidney disease in low-resource settings where serum creatinine is unavailable. BMJ Glob Health 5: e002312. 
59. Raimann JG, Kirisits W, Gebetsroither E, Carter M, Callegari J, Rosales L, Levin NW, Kotanko P, 2011. Saliva urea dipstick test: application in chronic kidney disease. Clin Nephrol 76: 23-28.

60. Calice-Silva V, Vieira MA, Raimann JG, Carter M, Callegari J, Levin NW, Kotanko P, Pecoits-Filho R, 2014. Saliva urea nitrogen dipstick - a novel bedside diagnostic tool for acute kidney injury. Clin Nephrol 82: 358-366.

61. Ponce D, Balbi A, 2016. Acute kidney injury: risk factors and management challenges in developing countries. Int $J$ Nephrol Renovasc Dis 9: 193-200.

62. Hoste EAJ, Kellum JA, Selby NM, Zarbock A, Palevsky PM, Bagshaw SM, Goldstein SL, Cerdá J, Chawla LS, 2018. Global epidemiology and outcomes of acute kidney injury. Nat Rev Nephrol 14: 607-625.

63. Lewington AJ, Cerda J, Mehta RL, 2013. Raising awareness of acute kidney injury: a global perspective of a silent killer. Kidney Int 84: 457-467.

64. Lunyera J, Kilonzo K, Lewington A, Yeates K, Finkelstein FO, 2016. Acute kidney injury in low-resource settings: barriers to diagnosis, awareness, and treatment and strategies to overcome these barriers. Am J Kidney Dis 67: 834-840.

65. Igiraneza G, Dusabejambo V, Finklestein FO, Rastegar A, 2020. Challenges in the recognition and management of acute kidney injury by hospitals in resource-limited settings. Kidney Int Rep 5: 991-999.

66. Mehta RL et al., 2015. International Society of Nephrology's Oby25 initiative for acute kidney injury (zero preventable deaths by 2025): a human rights case for nephrology. Lancet 385 : 2616-2643.

67. Sharma S, Zapatero-Rodríguez J, Estrela P, O’Kennedy R, 2015. Point-of-care diagnostics in low resource settings: present status and future role of microfluidics. Biosensors 5: 577-601.

68. Malcolm S, Cadet J, Crompton L, DeGennaro V, 2019. A model for point of care testing for non-communicable disease diagnosis in resource-limited countries. Glob Health Epidemiol Genom 4: e7.

69. Simeon K, Sharma M, Dorward J, Naidoo J, Dlamini N, Moodley P, Samsunder N, Barnabas RV, Garrett N, Drain PK, 2019. Comparative cost analysis of point-of-care versus laboratorybased testing to initiate and monitor HIV treatment in South Africa. PLoS One 14: 1-15.

70. Degennaro V, Malcolm S, Crompton L, Vaddiparti K, Mramba LK, Striley C, Cottler L, Taylor K, Leverence R, 2018. Communitybased diagnosis of non-communicable diseases and their risk factors in rural and urban Haiti: a cross-sectional prevalence study. BMJ Open 8: 1-8.

71. Pei $\mathrm{G}$ et al., 2020. Renal involvement and early prognosis in patients with COVID-19 pneumonia. J Am Soc Nephrol 31: 1157-1165.

72. Cui $X$ et al., 2020. Acute kidney injury in patients with the coronavirus disease 2019: a multicenter study. Kidney Blood Press Res 100029: 612-622.

73. Robbins-Juarez SY, Qian L, King KL, Stevens JS, Husain SA, Radhakrishnan J, Mohan S, 2020. Outcomes for patients with COVID-19 and acute kidney injury: a systematic review and meta-analysis. Kidney Int Rep 5: 1149-1160.

74. Xu J et al., 2020. Clinical course and predictors of 60-day mortality in 239 critically ill patients with COVID-19: a multicenter retrospective study from Wuhan, China. Crit Care 24: 1-11.

75. Gagliardi I, Patella G, Michael A, Serra R, Provenzano M, Andreucci M, 2020. COVID-19 and the kidney: from epidemiology to clinical practice. J Clin Med 9: 2506.

76. Adapa S, Chenna A, Balla M, Merugu GP, Koduri NM, Daggubati SR, Gayam V, Naramala S, Konala VM, 2020. COVID-19 pandemic causing acute kidney injury and impact on patients with chronic kidney disease and renal transplantation. J Clin Med Res 12: 352-361.

77. Lai CC, Ko WC, Lee PI, Jean SS, Hsueh PR, 2020. Extrarespiratory manifestations of COVID-19. Int $J$ Antimicrob Agents 56: 106024.

78. Guan W et al., 2020. Clinical characteristics of coronavirus disease 2019 in China. N Engl J Med 382: 1708-1720.

79. Su H et al., 2020. Renal histopathological analysis of 26 postmortem findings of patients with COVID-19 in China. Kidney Int 98: 219-227.
80. Golmai P, Larsen CP, DeVita MV, WahI SJ, Weins A, Rennke HG, Bijol V, Rosenstock JL, 2020. Histopathologic and ultrastructural findings in postmortem kidney biopsy material in 12 patients with AKI and COVID-19. J Am Soc Nephrol 31: 1944-1947.

81. Farouk SS, Fiaccadori E, Cravedi P, Campbell KN, 2020. COVID19 and the kidney: what we think we know so far and what we don't. J Nephrol 33: 1213-1218.

82. Rossi GM et al., 2020. Kidney biopsy findings in a critically ill COVID-19 patient with dialysis-dependent acute kidney injury: a case against "SARS-CoV-2 nephropathy." Kidney Int Rep 5: 1100-1105.

83. Santoriello D, Khairallah P, BombackAS, Xu K, KudoseS, Batal I, Barasch J, Radhakrishnan J, D'Agati V, Markowitz G, 2020. Postmortem kidney pathology findings in patients with COVID19. J Am Soc Nephrol 31: 2158-2167.

84. Larsen CP, Bourne TD, Wilson JD, Saqqa O, Sharshir MA, 2020. Collapsing glomerulopathy in a patient with COVID-19. Kidney Int Rep 5: 935-939.

85. Magoon S, Bichu P, Malhotra V, Alhashimi F, Hu Y, Khanna S, Berhanu K, 2020. COVID-19-Related glomerulopathy: a report of 2 cases of collapsing focal segmental glomerulosclerosis. Kidney Med 2: 488-492.

86. Ostermann M, Lumlertgul N, Forni LG, Hoste E, 2020. What every Intensivist should know about COVID-19 associated acute kidney injury. J Crit Care 60: 91-95.

87. Kazory A, Ronco C, McCullough PA, 2020. SARS-CoV-2 (COVID-19) and intravascular volume management strategies in the critically ill. Baylor Univ Med Cent Proc 33: 370-375.

88. Clark EG et al., 2020. CSN COVID-19 rapid review program: management of acute kidney injury. Can J Kidney Health Dis 7: 2054358120941679.

89. Ostermann M, Liu K, Kashani K, 2019. Fluid management in acute kidney injury. Chest 156: 594-603.

90. Acheampong A, Vincent JL, 2015. A positive fluid balance is an independent prognostic factor in patients with sepsis. Crit Care 19: 1-7.

91. Sirvent JM, Ferri C, Baró A, Murcia C, Lorencio C, 2015. Fluid balance in sepsis and septic shock as a determining factor of mortality. Am J Emerg Med 33: 186-189.

92. Koonrangsesomboon W, Khwannimit B, 2015. Impact of positive fluid balance on mortality and length of stay in septic shock patients. Indian J Crit Care Med 19: 708-713.

93. Silversides JA, Major E, Ferguson AJ, Mann EE, McAuley DF, Marshall JC, Blackwood B, Fan E, 2017. Conservative fluid management or deresuscitation for patients with sepsis or acute respiratory distress syndrome following the resuscitation phase of critical illness: a systematic review and meta-analysis. Intensive Care Med 43: 155-170.

94. Ostermann M, Oudemans-van Straaten HM, Forni LG, 2015. Fluid overload and acute kidney injury: cause or consequence? Crit Care 19: 19-21.

95. Garzotto $F$ et al., 2016. The dose response multicentre investigation on fluid assessment (DoReMIFA) in critically ill patients. Crit Care 20: 1-14.

96. Sakr Y, Birri R, Nahuel P, Kotfis K, Nanchal R, Shah B, Kluge S, Schroeder ME, Marshall JC, Vincent JL, 2017. On behalf of the intensive care over nations investigators. Higher fluid balance increases the risk of death from sepsis: results from a large international audit. Crit Care Med 45: 386-394.

97. MöhlenkampS, Thiele H, 2020. Ventilation of COVID-19 patients in intensive care units. Herz 45: 329-331.

98. Richardson $\mathrm{S}$ et al., 2020. Presenting characteristics, comorbidities, and outcomes among 5700 patients hospitalized with COVID-19 in the New York city area. J Am Med Assoc 10022: E1-E8.

99. Ali H, Daoud A, Mohamed MM, Salim SA, Yessayan L, Baharani J, Murtaza A, Rao V, Soliman KM, 2020. Survival rate in acute kidney injury superimposed COVID-19 patients: a systematic review and meta-analysis. Ren Fail 42: 393-397.

100. Perico L, Benigni A, Remuzzi G, 2020. Should COVID-19 concern nephrologists? why and to what extent? the emerging impasse of angiotensin blockade. Nephron 24126: 213-221.

101. Olowu WA, Niang A, Osafo C, Ashuntantang G, Arogundade FA, Porter J, Naicker S, Luyckx VA, 2016. Outcomes of acute 
kidney injury in children and adults in sub-Saharan Africa: a systematic review. Lancet Glob Health 4: e242-e250.

102. Chawla S, Kurani S, Wren SM, Stewart B, Burnham G, Kushner A, McIntyre T, 2018. Electricity and generator availability in LMIC hospitals: improving access to safe surgery. J Surg Res 223: 136-141.

103. Chijioke A, Makusiki A, Rafiu M, 2012. Factors influencing hemodialysis and outcome in severe acute renal failure from ilorin, Nigeria. Saudi J Kidney Dis Transpl 23: 391-396.

104. Odetunde OI, Okafor HU, Uwaezuoke SN, Ezeonwu BU, Ukoha OM, 2014. Renal replacement therapy in children in the developing world: challenges and outcome in a tertiary hospital in southeast Nigeria. Sci World J 2014: 903151.

105. Bello AK et al., 2018. Global overview of health systems oversight and financing for kidney care. Kidney Int Suppl 8: 41-51.

106. Carter M, Levin NW, Carter CS, Callegari J, 2016. The Sustainable Kidney Care Foundation's contribution to the improvement of AKI management in developing countries using peritoneal dialysis. Clin Nephrol 86: 78-83.

107. SmoyerWE, Finkelstein FO, McCulloch M, Carter M, Brusselmans A, Feehally J, 2015. Saving Young Lives: provision of acute dialysis in low-resource settings. Lancet 386: 2056.

108. Smoyer WE, Finkelstein FO, McCulloch MI, Carter M, Brusselmans A, Feehally J, 2016. "Saving Young Lives" with acute kidney injury: the challenge of acute dialysis in low-resource settings. Kidney Int 89: 254-256.

109. Vasudevan A, lyengar A, Phadke K, 2012. Modality of choice for renal replacement therapy for children with acute kidney injury: results of a survey. Indian J Nephrol 22: 121-124.

110. Abdou $\mathrm{N}$ et al., 2017. Peritoneal dialysis to treat patients with acute kidney injury-the saving Young Lives experience in West Africa: proceedings of the saving Young Lives session at the first international conference of dialysis in West Africa, Dakar, Senegal, December 2015. Perit Dial Int 37: 155-158.

111. Gabriel DP, Caramori JT, Martim LC, Barretti P, Balbi AL, 2008. High volume peritoneal dialysis vs daily hemodialysis: a randomized, controlled trial in patients with acute kidney injury. Kidney Int 73 (Suppl 108): S87-S93.

112. Sharma SK, Manandhar D, Singh J, Chauhan HS, Koirala B, Gautam M, Ghotekar LH, Tamang B, Gurung S, 2003. Acute peritoneal dialysis in eastern Nepal. Perit Dial Int 23 (Suppl 2): S196-S199.

113. Chionh CY, Soni SS, Finkelstein FO, Ronco C, Cruz DN, 2013. Use of peritoneal dialysis in AKI: a systematic review. Clin J Am Soc Nephrol 8: 1649-1660.

114. Arogundade FA, Ishola DA Jr., Sanusi AA, Akinsola A, 2005. An analysis of the effectiveness and benefits of peritoneal dialysis and haemodialysis using Nigerian made PD fluids. Afr $\mathrm{J}$ Med Med Sci 34: 227-233.

115. Parapiboon W, Ponce D, Cullis $B, 2020$. Acute peritoneal dialysis in COVID-19. Perit Dial Int 40: 359-362.

116. Shamy OEl, Patel N, Abdelbaset MH, Chenet L, Tokita J, Lookstein R, Lee DS, Cohen NA, Sharma S, Uribarri J, 2020. Acute start peritoneal dialysis during the COVID-19 pandemic: outcomes and experiences. J Am Soc Nephrol 31: 1680-1682.

117. Vigiola Cruz M, Bellorin O, Srivatana V, Afaneh C, 2020. Safety and efficacy of bedside peritoneal dialysis catheter placement in the COVID-19 Era: initial experience at a New York city hospital. World J Surg 44: 2464-2470.

118. Vischini G, D’Alonzo S, Grandaliano G, D’Ascenzo FM, 2020. SARS-CoV-2 in the peritoneal waste in a patient treated with peritoneal dialysis. Kidney Int 98: 237-238.

119. Liu L, Zhang L, Liu GJ, Fu P, 2017. Peritoneal dialysis for acute kidney injury. Cochrane Database Syst Rev 2017: 2-4.

120. Ponce D, Balbi AL, Durand JB, Moretta G, Divino-Filho JC, 2020. Acute peritoneal dialysis in the treatment of COVID-19-related acute kidney injury. Clin Kidney J 13: 269-273.

121. George J, Varma S, Kumar S, Thomas J, Gopi S, Pisharody R, 2011. Comparing continuous venovenous hemodiafiltration and peritoneal dialysis in critically ill patients with acute kidney injury: a pilot study. Perit Dial Int 31: 422-429.

122. Okpechi IG, Rayner BL, Swanepoel CR, 2012. Peritoneal dialysis in Cape town, South Africa. Perit Dial Int 32: 254-260.
123. Savla D, Ahmed S, Yeates K, Matthew A, Anand S, 2017. Barriers to increasing use of peritoneal dialysis in Bangladesh: a survey of patients and providers. Perit Dial Int 37: 234-237.

124. Kilonzo KG, Ghosh S, Temu SA, Maro V, Callegari J, Carter M, Handelman G, Finkelstein FO, Levin N, Yeates K, 2012. Outcome of acute peritoneal dialysis in northern Tanzania. Perit Dial Int 32: 261-266.

125. Dhanakijcharoen $P$, Sirivongs $D$, Aruyapitipan $S$, Chuengsaman $\mathrm{P}$, Lumpaopong A, 2011. The "PD first" policy in Thailand: three-years experiences (2008-2011). J Med Assoc Thai 94 (Suppl 4): S153-S161.

126. Kilonzo KG, Akrabi HF, Yeates KE, 2020. Cost-effectiveness of acute peritoneal dialysis: considerations from Africa. Clin Nephrol 93: 72-75.

127. Obiagwu PN, Abdu A, 2015. Peritoneal dialysis vs. haemodialysis in the management of paediatric acute kidney injury in Kano, Nigeria: a cost analysis. Trop Med Int Health 20: 2-7.

128. Karopadi AN, Mason G, Rettore E, Ronco C, 2013. Cost of peritoneal dialysis and haemodialysis across the world. Nephrol Dial Transpl 28: 2553-2569.

129. McCulloch MI, Nourse P, Argent AC, 2020. Use of locally prepared peritoneal dialysis (PD) fluid for acute $P D$ in children and infants in Africa. Perit Dial Int 40: 441-445.

130. Esezobor Cl, Ladapo TA, Lesi FE, 2014. Peritoneal dialysis for children with acute kidney injury in Lagos, Nigeria: experience with adaptations. Perit Dial Int 34: 534-538.

131. Palmer D et al., 2018. Peritoneal dialysis for AKI in Cameroon: commercial vs locally-made solutions. Perit Dial Int 38: 246-250.

\section{APPENDIX}

Development of recommendations and suggestions. Selection of Task Force members. The selection of the group members was based on interest in specific aspects of novel coronavirus disease (COVID-19) and direct experience in low- and middle-income countries (LMICs). Alfred Papali and Marcus Schultz contacted potential team members through email and in person early in the COVID-19 pandemic, and created ten subgroups assigned to separate areas in COVID-19 management, i.e., 'triage', 'safety', 'organization', 'diagnostics', 'acute respiratory failure', 'acute kidney injury', 'coagulopathy, 'therapeutics', 'shock' and 'support after initial care'. In total, there were 38 Task Force members representing five medical specialties or disciplines (emergency medicine, intensive care, infectious diseases, internal medicine and critical care nursing) from five out of six World Health Organization (WHO) geographic regions. The Task Force consisted of 16 full-time LMIC members, 16 fulltime high-income country (HIC) members-all with direct

TABLE A1

Quality of evidence

\begin{tabular}{lll}
\hline A & Randomized clinical trials & High \\
B & $\begin{array}{l}\text { Downgraded randomized clinical trial(s) or } \\
\text { upgraded observational studies }\end{array}$ & Moderate \\
& $\begin{array}{l}\text { Observational studies } \\
\text { Downgraded observational studies or } \\
\text { expert opinions }\end{array}$ & Low \\
D & Very low \\
& & \\
\hline
\end{tabular}
Factors that may decrease strength of evidence include high likelihood of bias; inconsistency of results, including problems with subgroup analyses; indirectness of evidence (other population, intervention, control, outcomes, comparison); imprecision of findings; and likelihood of reporting bias. Factors that may increase strength of evidence: large magnitude of effect (direct evidence, relative risk $>2$ with no plausible confounders); very large magnitude of effect with relative risk $>5$ and no threats to validity (by two levels); and dose-response gradient. Adapted from Dondorp AM, Dünser MW, Schultz MJ, eds., 2019. Sepsis Management in Resource-limited Settings. Springer. doi.org/10.1007/978-3-030- 
TABLE A2

Strong vs. weak recommendations*

\begin{tabular}{|c|c|}
\hline What is Considered & How it affects the recommendation \\
\hline High evidence & The higher the quality of evidence, the more likely a strong recommendation. \\
\hline $\begin{array}{l}\text { Certainty about the balance of benefits vs. } \\
\text { harms and burdens }\end{array}$ & $\begin{array}{l}\text { The larger/smaller the difference between the desirable and undesirable consequences and the } \\
\text { certainty around that difference, the more likely a strong/weak recommendation. }\end{array}$ \\
\hline Certainty in or similar values & $\begin{array}{l}\text { The more certainty or similarity in values and preferences, the more likely a strong } \\
\text { recommendation. }\end{array}$ \\
\hline Resource implications & $\begin{array}{l}\text { The lower/higher the cost of an intervention compared to the alternative the more likely a strong/ } \\
\text { weak recommendation. }\end{array}$ \\
\hline Availability and feasibility iLMICs & The less available, the more likely a weak recommendation. \\
\hline Affordability for LMICs & The less affordable, the more likely a weak recommendation. \\
\hline Safety of the intervention in LMICs & The less safe in an LMIC, the more likely a weak recommendation. \\
\hline
\end{tabular}

LMIC experience-and 6 members with joint LMIC/HIC appointments.

Selection of subgroup members. Kristina Rudd, Elif Çizmeci, Gabriela Galli, Ganbold Lundeg, Marcus Schultz, and Alfred Papali were assigned to this subgroup based on their specific expertise and interest in the prevention, diagnosis, and treatment of infection-associated acute kidney injury in LMICs.

Meetings. An initial online meeting of the subgroup heads was held to establish the procedures for literature review and drafting of tables for evidence analysis. The subgroup heads continued to coordinate work across the project via the internet. Several meetings occurred through teleconferences and electronic-based discussions among the subgroup heads and with members of other subgroups.

In the first meetings, a set of clearly defined questions was outlined. These were reviewed for content and clarity by the subgroup members and heads from the other subgroups. After approval by the subgroup members and heads from the other subgroups, the subgroup members performed a literature review, seeking evidence for recommendations regarding the specific questions posed. During this process, questions could be combined, so the subgroup heads were finally left with four major questions. The subgroup heads summarized the evidence in an online supplement, and formulated a set of recommendations and suggestions after online discussions. These were communicated among the subgroup members. After their approval, the subgroup heads summarized the evidence in a report, which was sent for approval by all members of the Task Force.
Search techniques. The literature search was performed in PubMed and OVID, including articles pertaining to COVID-19, other respiratory viruses, and infection-related AKI. Furthermore, the subgroup members evaluated the references of the identified papers to identify additional relevant publications. The search for questions 1 and 4 was performed on August 14, 2020 and the search for questions 2 and 3 was performed on August 17, 2020. These searches included all results published through the date of the search.

Grading of Recommendations. The subgroup members classified quality of evidence as high, moderate, low, or very low, and recommendations as strong or weak. The factors influencing this classification are presented in Table 1.

The subgroup members paid extensive attention to availability, feasibility, affordability, and safety in LMICs. A strong recommendation was worded as 'we recommend' and a weak recommendation as 'we suggest' (Table 2).

Reporting. The report was edited for style and form by Kristina Rudd and Alfred Papali, with final approval by subgroup heads and then by the entire 'COVID-LMIC Task Force'.

Conflicts of interest. No members of the 'Acute Kidney Injury' subgroup represented industry, and there was no industry input into guidelines development. No member of the 'Acute Kidney Injury' subgroup received honoraria for any role in the guideline development process. None reported conflicts of interest.

Open access fees for this manuscript, and all 9 others in the series, were supported by the Wellcome Trust of Great Britain. 